\title{
Structural, Morphological, Vibrational and Optical Properties of GaN Films Grown by Reactive Sputtering: The Effect of RF Power at Low Working Pressure Limit
}

\author{
R. S. de Oliveira ${ }^{a}$ H. A. Folli ${ }^{a}$, C. Stegemann ${ }^{b}$ I. M. Horta ${ }^{a}$ B. S. Damasceno ${ }^{a}$ W. Miyakawa , \\ A. L. J. Pereira ${ }^{a}$, M. Massid ${ }^{d}$ (D, A. S. da Silva Sobrinho ${ }^{a}$ (D) D. M. G. Leite ${ }^{*}$ (D) \\ aInstituto Tecnológico de Aeronáutica (ITA), Laboratório de Plasmas e Processos (LPP), \\ São José dos Campos, SP, Brasil. \\ ${ }^{b}$ Faculdade de Tecnologia SENAI Jaraguá do Sul, Jaraguá do Sul, SC, Brasil. \\ 'Instituto de Estudos Avançados (IEAv), São José dos Campos, SP, Brasil. \\ ${ }^{d}$ Universidade Presbiteriana Mackenzie, Escola de Engenharia (PPGEMN), São Paulo, SP, Brasil.
}

Received: August 27, 2021; Revised: November 16, 2021; Accepted: December 8, 2021

\begin{abstract}
This work reports the properties of GaN films grown onto c-Si (100) at relatively low substrate temperature $\left(400^{\circ} \mathrm{C}\right)$ by reactive magnetron sputtering. The study depicts the effect of working pressure and RF power on the GaN film structural, vibrational and optical properties characterized by X-ray diffraction, atomic force and scanning electron microscopies, Raman spectroscopy and spectroscopic ellipsometry. Unusual low pressure deposition condition $(0.40 \mathrm{~Pa})$ was achieved by using a separated argon inlet directed to the Ga target surface, resulting in improved crystalline quality of the films. In this condition, the preferential crystalline orientation, the surface morphology and the optical gap of the GaN films show a strong dependence on the RF power applied to the Ga target, where low RF power (30-60 W) was responsible for increasing the $c$-axis orientation and the optical gap, while higher RF power (75-90 W) decreased the overall crystal quality and increased the surface roughness.
\end{abstract}

Keywords: GaN, reactive sputtering, thin film.

\section{Introduction}

$\mathrm{GaN}$ is a direct wide band gap $(3.4 \mathrm{eV})$ semiconductor with high electronic mobility and high melting temperature $\left(2,500^{\circ} \mathrm{C}\right)^{1}$. The GaN attractive properties enabled the advent of blue and UV light emitting diodes (LEDs) and lasers, and also the improvement in many other applications as high-power and high electron-mobility transistors (HEMT) ${ }^{2-5}$. The GaN piezoelectric properties have also assured its application in high frequency (above $5 \mathrm{GHz}$ ) filters and sensors, overtaking consolidated materials such as $\mathrm{ZnO}$ and AlN in some situations ${ }^{6,7}$.

The reactive sputtering technique is a simple and relatively low-cost technique for GaN film growth, allowing the use of low growth temperatures, high deposition rates, and is compatible with most substrates, in a wide range of sizes ${ }^{8,9}$. Temperatures below $600{ }^{\circ} \mathrm{C}$ strongly favor a preferential growth of the crystalline axis $\mathrm{c}$, that is, in the $<0002>$ direction ${ }^{10}$. This is a great advantage since obtaining high-quality crystalline and electronic-grade $\mathrm{GaN}$ is almost always linked to the use of sapphire $\left(\mathrm{Al}_{2} \mathrm{O}_{3}\right)$ and/or silicon carbide ( $\mathrm{SiC}$ ) substrates, which are offered in small sizes and at extremely high prices. In this sense, the growth of $\mathrm{GaN}$ onto silicon substrates ${ }^{11-14}$ stands out among efforts to reduce costs and increase compatibility with current technologies ${ }^{15}$. Besides, although known to obtain generally amorphous or polycrystalline films, the reactive sputtering has recently achieved GaN and AlN epitaxial films ${ }^{16-21}$.

*e-mail: leite@ita.br
Even with a micro or nanocrystalline structure, GaN growth by sputtering is of great interest in applications that consider the piezoelectric character of the material. This characteristic makes it interesting for application in surface acoustic waves (SAW) filters and sensors, and other high frequency devices ${ }^{22-24}$. In this scenario, there is still a significant demand for practical studies in order to optimize and understand the role of the main deposition parameters on the physical properties of GaN films grown by sputtering using different deposition setups ${ }^{25}$. More specifically, and even knowing that low working pressure and $\mathrm{N}_{2}$-rich plasmas are beneficial in order to achieve epitaxial conditions in sputtered III-nitrides, there is a significant lack of works reporting the low working pressure regime limit $(<0.67 \mathrm{~Pa})$, mostly due to the difficult of sustaining $\mathrm{N}_{2}$-rich plasma in such low pressure ${ }^{18,25,26}$.

Therefore, this work presents a study of the structural, morphological, vibrational and optical properties of GaN films deposited onto c-Si (100) by reactive RF magnetron sputtering, using a new dedicated deposition setup. By directing the argon inlet to the Ga target surface, it was possible to achieve the unusual deposition working pressure of $0.40 \mathrm{~Pa}$, even with $\mathrm{N}_{2}$-rich atmosphere $(67 \%)$, where the RF power study was then employed. X-ray diffraction technique was extensively explored in order to determine the crystallographic phase, lattice parameters, crystallite sizes and preferential orientation of each sample. The surface morphology of selected films was examined by atomic force and scanning 
electron microscopies. Raman spectroscopy was employed to highlight the lattice vibrational modes under resonant UV excitation. The optical parameters refraction index, extinction coefficient, and band-gap energy were determined from spectroscopic ellipsometry in the UV-Vis-NIR spectra.

\section{Experimental Details}

\subsection{Reactive sputtering setup}

This is the first report of a recently assembled GaN-dedicated setup based on an UHV stainless steel chamber (standard spherical KJ Lesker, P/N SP1800S-316LN-EP) with ConFlat ${ }^{\circ}$ flanges, equipped with a turbo molecular pump (NEXT 400 Edwards) system, and capable of reaching residual pressures of $5^{\times} 10^{-5} \mathrm{~Pa}$ at room temperature (RT). A 4-inches diameter Torous ${ }^{\circledR}$ circular $\mathrm{HV}$ magnetron $(\mathrm{P} / \mathrm{N}$ TM4AS10PXF) was adapted to work with targets in liquid form (210 g of $99.999 \% \mathrm{Ga}$, Process Materials Inc.), as detailed in Figure 1. It is powered by a $13.56 \mathrm{MHz}$ RF power supply (600W KJLC-R601) equipped with automatic matching box. The magnetron shield has a gas injection ring, which was used to direct the argon flow to the Ga target surface, represented in Figure 1. The substrate holder is a $100 \mathrm{~mm}$ wafer UHV manipulator built by the VST - Israel (P/N 71658), with an IR-lamp heating (up to $650{ }^{\circ} \mathrm{C}$ - calibrated with optical pyrometer), z-axis regulation ( $100 \mathrm{~mm}$ course), and rotatory (1 to $40 \mathrm{rpm}$ ) systems.

The $\mathrm{N}_{2}$ inlet pipe is directed to the substrate's surface, symmetrically positioned in relation to the vacuum outlet flange, as shown in Figure 1. This configuration provides a richer $\mathrm{N}_{2}$ plasma, which has a beneficial effect to the sample crystalline quality ${ }^{10,27}$. A minimum Ar gas flow (adjusted from our preliminary experiments) was injected directly to the Ga target surface by an injection ring installed onto the magnetron shield. It allows to avoid target-poisoned regime, favors higher growth rates, and allows the achievement of very low working pressure regime ${ }^{28,29}$. Both gas flows $\left(\mathrm{N}_{2}\right.$ and Ar) are precisely controlled by individual MKS mass flow heads and MKS Type 247 Four-Channel Readout.

\subsection{Deposition procedure}

Silicon wafers (University-Wafer - $100 \mathrm{~mm}$ diameter, single-side polished, 10-20 Ohms) were cleaved in smaller pieces (about $15 \mathrm{~mm} \times 15 \mathrm{~mm}$ ), and cleaned by the standard RCA procedure. In each experiment, six of those pieces were attached to the $100 \mathrm{~mm}$ stainless steel substrate holder disk $90 \mathrm{~mm}$ above the Ga liquid surface. Before deposition, substrates were heated up to $450^{\circ} \mathrm{C}$ for 30 minutes to outgas their surfaces up to $3 \times 10^{-4} \mathrm{~Pa}$ residual pressure. Substrates were then left to cool down to the deposition temperature $\left(400^{\circ} \mathrm{C}\right.$, monitored by an optical pyrometer), and 30 minutes later the deposition process started, assuring uniform and stabilized substrate temperature. During the deposition, the substrates rotated at $6 \mathrm{rpm}$, to guarantee a homogeneous temperature $\left(<1^{\circ} \mathrm{C}\right.$ variation along the substrate holder $)$. The $\mathrm{N}_{2}$ :Ar flow rate of $14: 7 \mathrm{sccm}$ and the 120 min deposition time are parameters chosen from preliminary tests.

The first step of the present study was the evaluation of the working pressure effects, keeping the RF power constant,

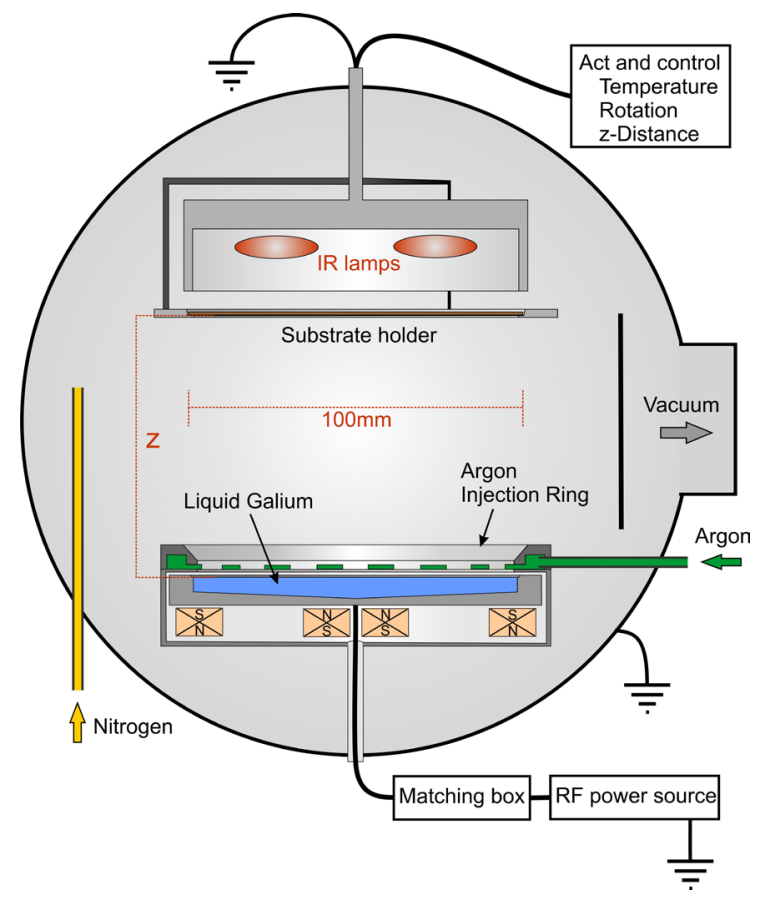

Figure 1. Schematic representation of the deposition chamber, showing the cylindrical magnetron and the substrate holder.

at $60 \mathrm{~W}$. The tested working pressures were $0.40,0.67,1.33$, and $2.67 \mathrm{~Pa}$. It is worth to mention that the lower working pressure $(0.40 \mathrm{~Pa})$ was obtained using $21 \mathrm{sccm}$ total mass flow rate, with the vacuum outlet gate valve almost totally open, and the turbo molecular pump at $60 \%$ of its total speed. This configuration helps to minimize the residual contamination and also avoids the $\mathrm{N}_{2}$ target-poisoning ${ }^{30}$, by forced renewed plasma atmosphere, mainly by injecting the $\mathrm{Ar}$ gas separately direct on the Ga target surface. The poisoning of the liquid Ga target can be easily noted by the formation of a thin solid layer. This poisoning layer was noted using working pressure above $1.33 \mathrm{~Pa}$. For 0.40 and $0.67 \mathrm{~Pa}$, most of the Ga target (particularly the circular track formed by the magnetron system) was clean and only metallic liquid Ga target was noticed.

From the preliminary tests, the lower pressure limit to sustain the plasma was $0.40 \mathrm{~Pa}$, which is well below the literature values (some above $0.67 \mathrm{~Pa}$, and most of them above $1.0 \mathrm{~Pa})^{18,25}$. Therefore, this pressure was the chosen for the systematic study of the RF power influence, which was taken at $30,45,60,75$ and $90 \mathrm{~W}$.

As a good practice to avoid artifacts (false behaviors influenced by "memory effect"), all samples were grown out of logical crescent sequence, i.e., for working pressure variation, the sequence was: $0.67 \rightarrow 1.33 \rightarrow 0.40 \rightarrow 2.67 \mathrm{~Pa}$, and for the RF power: $60 \rightarrow 90 \rightarrow 45 \rightarrow 75 \rightarrow 30 \mathrm{~W}$. The reproducibility was also confirmed by repeating the experiments with same deposition parameters.

\subsection{Characterizations}

The samples were analyzed by X-ray diffractometry, using a PANalytical Empyrean, with $\mathrm{Cu}$ target $\left(\mathrm{K}_{\alpha}\right.$ radiation 
$1.5418 \AA$ ), under $40 \mathrm{kV}$ and $40 \mathrm{~mA}$. Measurements were performed in a Theta-2Theta geometry, $2 \theta$ varying from $25^{\circ}$ to $67^{\circ}$, at $0.05^{\circ} / \mathrm{s}$ scan speed. The presented diffractograms were not normalized and the lattice parameters ( $a$ and $c$ ) were determined from both (0002) and (1011) peak positions, simultaneously.

The GaN thin films morphologies were examined by field emission gun scanning electron microscopy (FEG-SEM), using a Tescan microscope, model MIRA 3 and by atomic force microscopy (AFM), using a Shimadzu scanning probe microscope, model SPM 9500J3.

Raman analyses were performed at RT, using a LabRAM HR Evolution confocal Raman microscope by HORIBA, with a $325 \mathrm{~nm}$ laser and a 100x objective. Special care was taken to avoid surface recrystallization due to a possible localized heat from the laser absorption.

The optical properties (bandgap, $\mathrm{E}_{\mathrm{g}}$, refractive index, $\mathrm{n}$, and extinction coefficient, $\mathrm{k}$ ) and the film thickness were determined using a HORIBA UVISEL 2 spectroscopic ellipsometry, operating with an incidence angle of 70, the spectral analysis and fitting regions ranged from 1.5 to $5.5 \mathrm{eV}$. The model and fitting processes were designed and performed in a Delta-Psi2 software (by HORIBA). The model used for all samples was composed of the Si-substrate, the GaN layer (thickness h), and a $50 \% \mathrm{GaN}-50 \%$ air top layer (thickness dh), to simulate the surface roughness. The GaN material was described by the Adachi New-Forouhi model ${ }^{31}$, which also gives the band gap energy $\left(\mathrm{E}_{\mathrm{g}}\right)$ as an adjusted parameter. The measured film thicknesses were confirmed by a mechanical profilometer KLA Tencor P7.

\section{Results and Discussion}

\subsection{Structural and morphological properties}

The dependence of the film thickness on the working pressure and on the applied RF power is presented in Figure 2. In both cases, a quasi-linear behavior was observed, inversely proportional to the working pressure and directly to the applied RF power. The deposition rate can be more easily controlled by adjusting the RF power. Comparing the thicknesses data at $30 \mathrm{~W}$ and $90 \mathrm{~W}(77 \mathrm{~nm}$ and $707 \mathrm{~nm}$, respectively), the deposition rate is about one order of magnitude by just tripling the RF power $(6 \mathrm{~nm} / \mathrm{min}$ at $90 \mathrm{~W}$, and $0.6 \mathrm{~nm} / \mathrm{min}$ at $30 \mathrm{~W}$ ).

Figure 3 and Figure 4 show the $\mathrm{X}$-ray diffractograms as functions of the working pressures and RF powers, respectively. In both, only $\mathrm{GaN}$ wurtzite phase peaks corresponding to the (1010), (0002), and (1011) planes were observed, in addition to the narrow peaks of the (100) Si substrate.

In Figure 3, except at $0.40 \mathrm{~Pa}$, the GaN-related peaks presented low intensities, suggesting amorphous matrixes with some inclusions of low-quality crystallites. The more pronounced (0002) peak at the lowest pressure $(0.40 \mathrm{~Pa})$ indicates a more crystallized film, probably composed by good quality and $c$-axis oriented crystallites ${ }^{33}$, motivating the choice of this working pressure for the systematic RF power study.

In Figure 4a, the first three main diffraction peaks were observed for 2Theta in the range 30-40 degrees (highlighted in Figure 4b), in addition to very low intensities (1012)
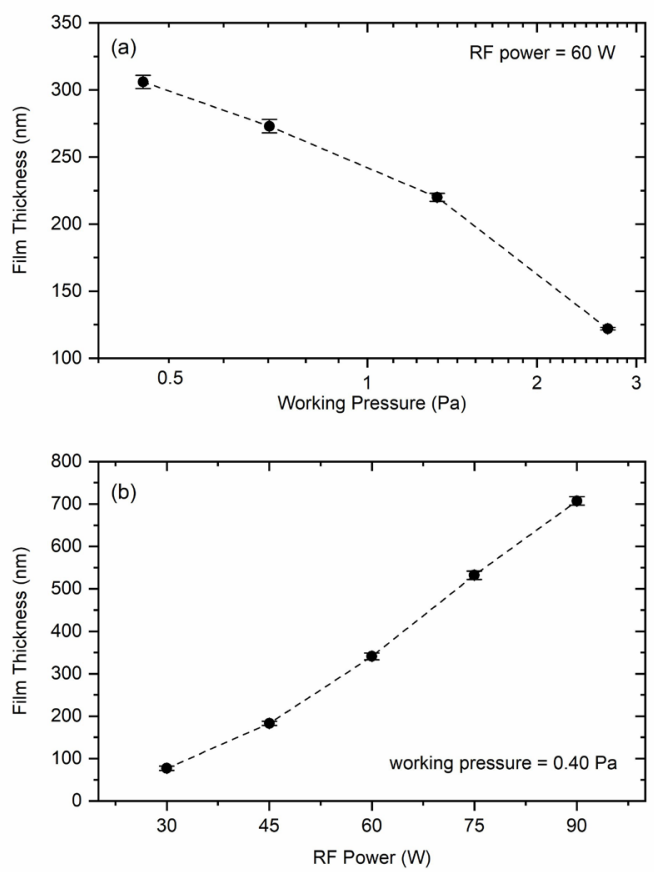

Figure 2. Curves of film thickness as function of (a) the working pressure and (b) the RF power. The error bar was smaller than the plotting point size.

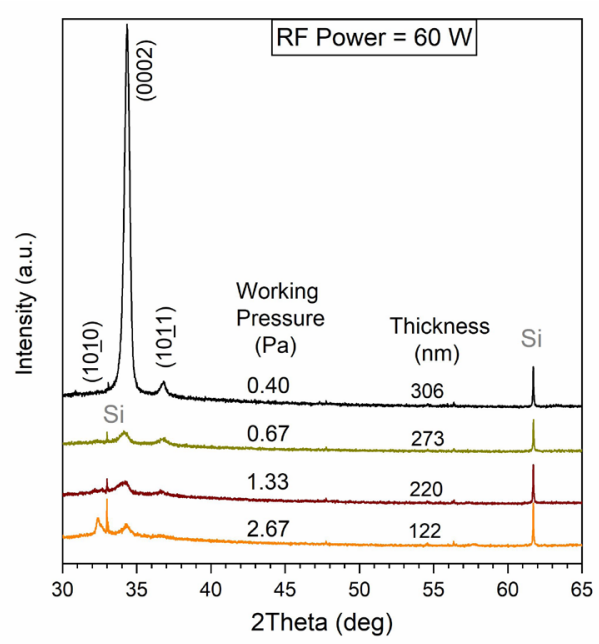

Figure 3. X-ray diffractograms of the GaN/Si films grown at different working pressures. The $\mathrm{Si}$ substrate narrow peaks are observed at $\sim 33$ and $\sim 62$ degrees. The film thicknesses are also indicated on the curves.

and (1013) peaks on the $90 \mathrm{~W}$ sample. As Si peaks were observed in all samples, even for the thicker one $(707 \mathrm{~nm})$, it is reasonable to assume that the $\mathrm{GaN}$ peaks came from the whole film thickness. Hence, in Figure 4b, the crescent behavior of the (0002) peak intensities observed from $30 \mathrm{~W}$ to $60 \mathrm{~W}$ can be directly related to the greater volume of 
crystallized material as the film becomes thicker. On the other hand, in the $60-90 \mathrm{~W}$ range, the (0002) peaks were becoming lower and broaden. Despite the crescent behavior of the (1011) peak, the samples grown at $75 \mathrm{~W}$ and $90 \mathrm{~W}$ have low crystallized fraction and/or low crystal quality.

The lattice parameters were calculated from the peak positions and presented in Figure 5a. Both $a$ and $c$ parameters tend to show an overall and slight decrease with increasing RF power, varying from 3.216 to $3.188 \AA$ and from 5.246 to $5.238 \AA$, respectively. Whereas the expected values for epitaxial GaN, also indicated in Figure 5a, are 3.189 and $5.186 \AA$, respectively ${ }^{1,34}$. From this comparison, it is clear that the obtained $c$ parameter values are significantly above than the expected one, while the $a$ parameter values are quite close to the reference (exception for the $30 \mathrm{~W}$ sample where the (1011) peak is very weak thus resulting in a relatively high uncertainty). These observations have an important
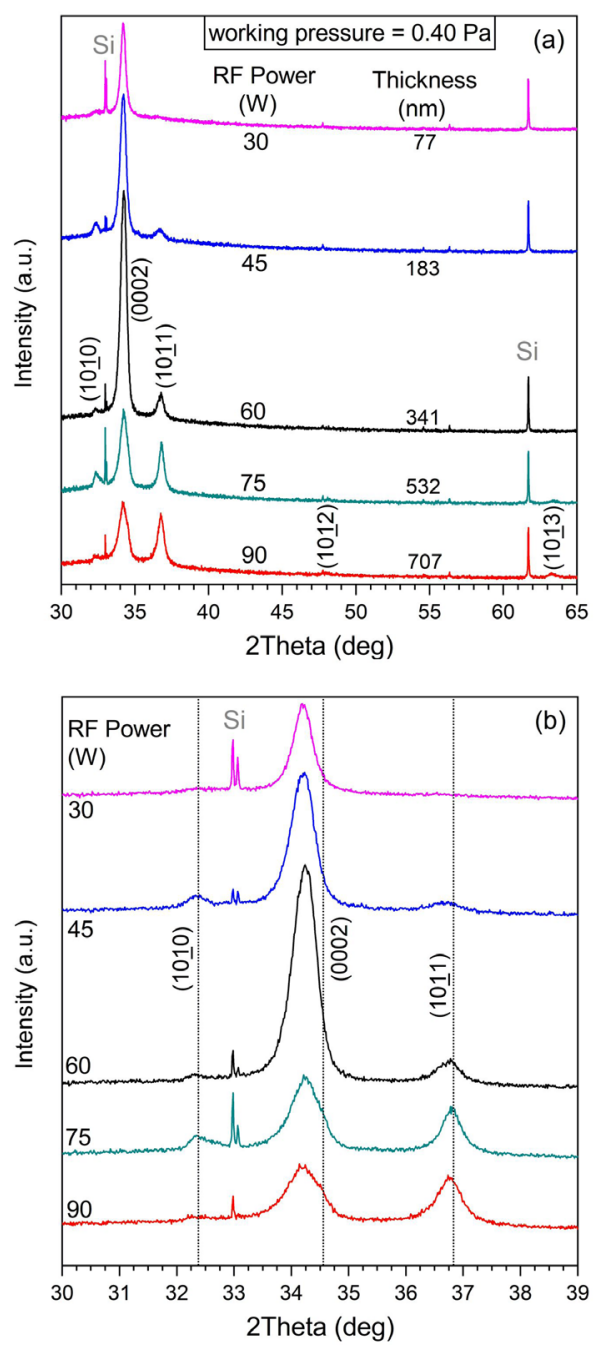

Figure 4. (a) X-ray diffractograms of the GaN/Si films grown using different RF power. (b) Expanded scale in the interval $30^{\circ}-40^{\circ}$, showing the main diffraction peaks and respective expected degree positions (vertical dashed lines), according to Schulz and Thiemann ${ }^{32}$. implication in the $c / a$ aspect ratio, plotted as the left axis of Figure $5 \mathrm{~b}$, from where it can be observed that the $c / a$ ratio starts at 1.63 for RF power of $30 \mathrm{~W}$ and establishes around 1.64 for RF powers above $45 \mathrm{~W}$. For comparison, the value observed for most epitaxial GaN films are $1.626 \pm 0.002^{1,34}$, while the expected value for ideal wurtzite is 1.633 .

Evaluating the relative peak intensities in Figure 4, a preferential diffraction in the (0002) plane was noted. Expectations were that this plane would be the third most intense peak in homogeneous and random distributed crystallites, the first one being the (1011) and the second, the $(1010)^{32}$. These higher intensities at the (0002) planes are indicatives of crystallites mostly oriented with the $c$-axis perpendicular to the substrate surface. In order to analyze the RF power effect onto the $c$-orientation, a relative intensity parameter was calculated taking into account the (0002) and (1011) peaks, shown as the right axis of Figure $5 \mathrm{~b}$. It is possible

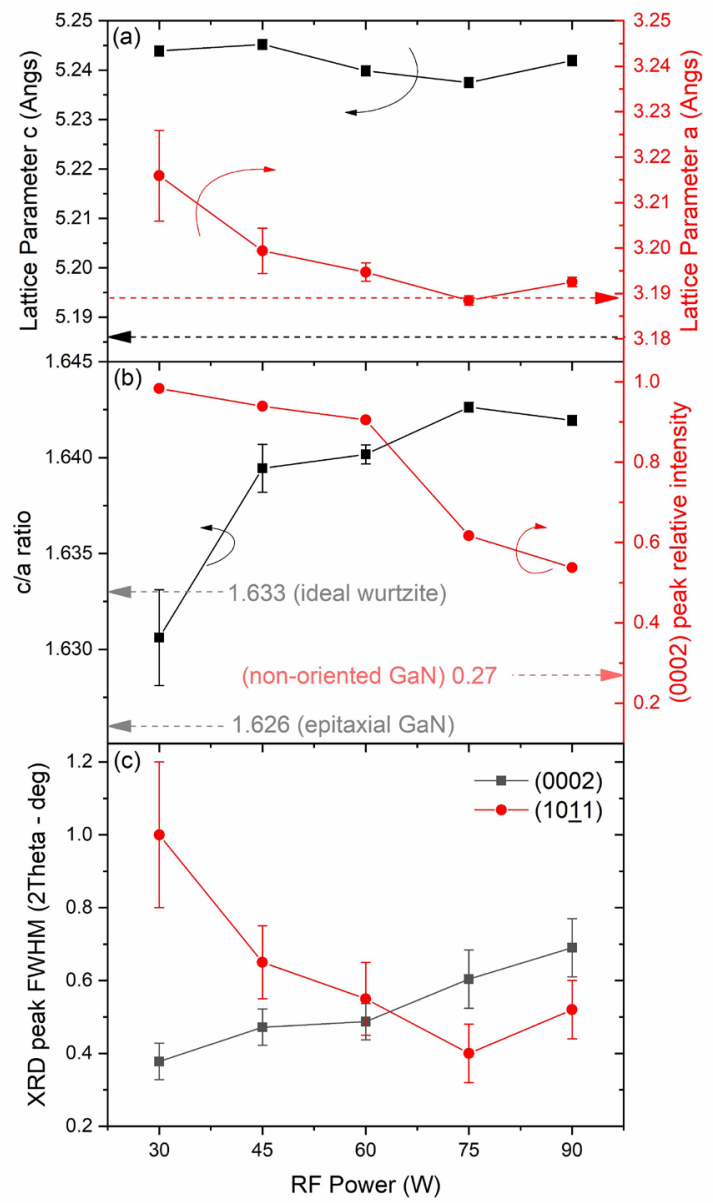

Figure 5. (a) Lattice parameters a (circles, right axis) and c (squares, left axis). The horizontal dashed arrows indicate the respective values for relaxed $\mathrm{GaN}$ according to ${ }^{1}$; (b) c/a lattice parameter ratio (squares, left axis) and the (0002) peak relative intensity (circles, right axis). The horizontal dashed arrows indicate the c/a value for epitaxial $\mathrm{GaN}$ according to ${ }^{1}$; (c) (0002) and (1011) peaks FWHM versus applied RF powers. 
to observe a decrescent behavior with the RF power, more intense between $60 \mathrm{~W}$ and $75 \mathrm{~W}$, but remaining above the expected for non-oriented $\mathrm{GaN}$.

The full width at half maximum (FWHM) of the (0002) and (1011) diffraction peaks are presented in Figure 5c, as a function of the RF power for the samples grown at $0.40 \mathrm{~Pa}$. The (0002) FWHM values showed a slow but continuous increase with the RF power, while those for (1011) peak exhibited an opposite behavior, following the relation: the higher the peak intensity, the lower the FWHM. The average crystallite sizes, as estimated by the Scherrer Formula ${ }^{35}$ from (0002) peak FWHM, were in the $20-40 \mathrm{~nm}$ range.

Figure 6 shows representative AFM and SEM images of samples grown at $0.40 \mathrm{~Pa}$ and 30,60 and $90 \mathrm{~W}$, evincing excellent agreement between the microscopies. The GaN films deposited were generally uniform, homogeneous and flat, with no failures, cracks or holes. At $60 \mathrm{~W}$, both micrographs
(Figure $6 \mathrm{~b}$ and e) revealed a surface formed by densely packed round nanoparticles, approximately $30-40 \mathrm{~nm}$ wide, and a total height variation lower than $25 \mathrm{~nm}$. However, at $30 \mathrm{~W}$, the images (Figure 6a and $\mathrm{d}$ ) have shown a different pattern: the GaN film was composed of several round-shaped clusters, with distinct dimensions in the interval from 30 to $100 \mathrm{~nm}$ wide, randomly dispersed over a flat surface, similar to the GaN film surface at $60 \mathrm{~W}$. At $90 \mathrm{~W}$, the surface was constituted of elongated structures (about 15-60 nm wide, $50-150 \mathrm{~nm}$ long) as depicted in Figure $6 \mathrm{c}$ and $\mathrm{f}$.

Roughness parameters were calculated using the Shimadzu SPM9500 Series Offline software v2.4, and data are presented in Table 1. The most common parameters to characterize the surface profile are the arithmetical mean roughness $R_{a}$ (arithmetic average of heights and depths measured from a mean line, at $z=0$ ), the average maximum height roughness $R_{z}$ (average of the 10 maximum peak-valley distances), and

\section{AFM}
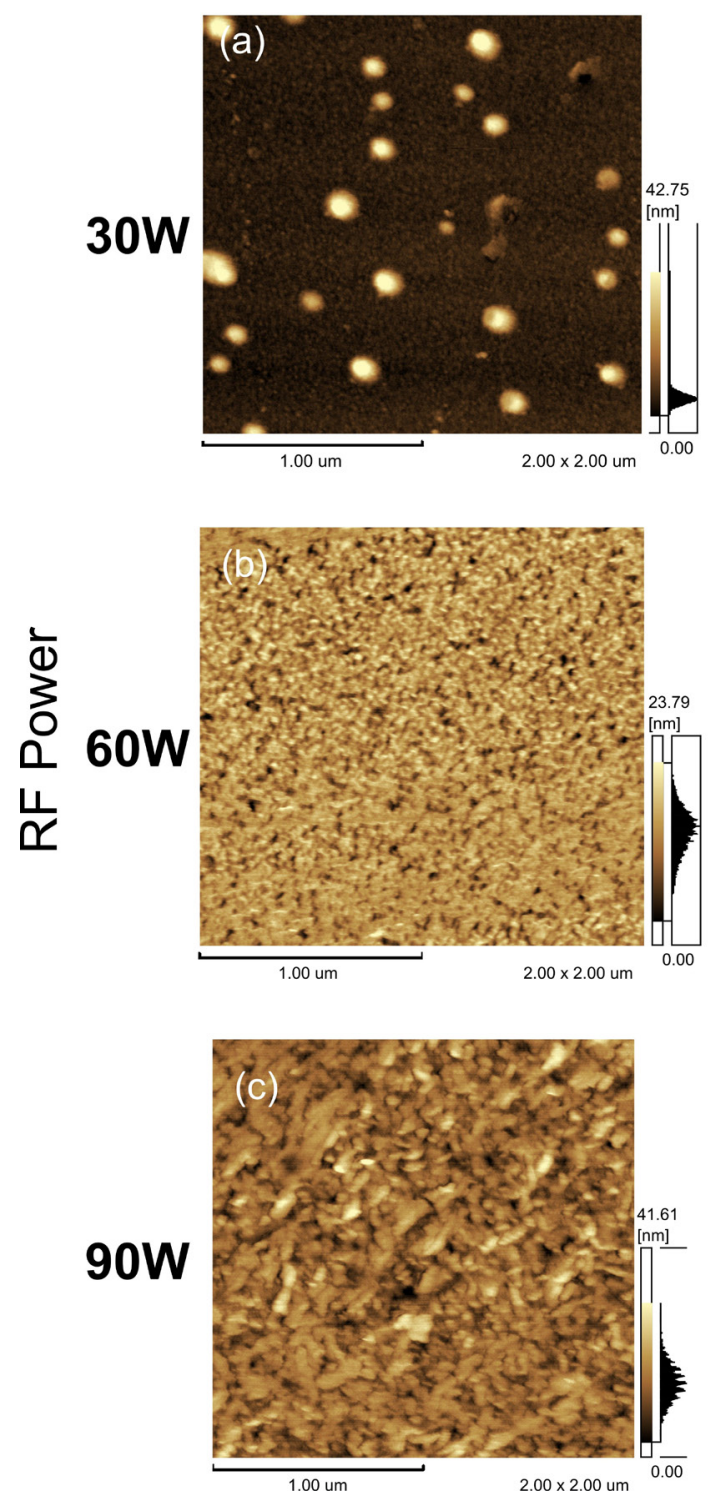

SEM
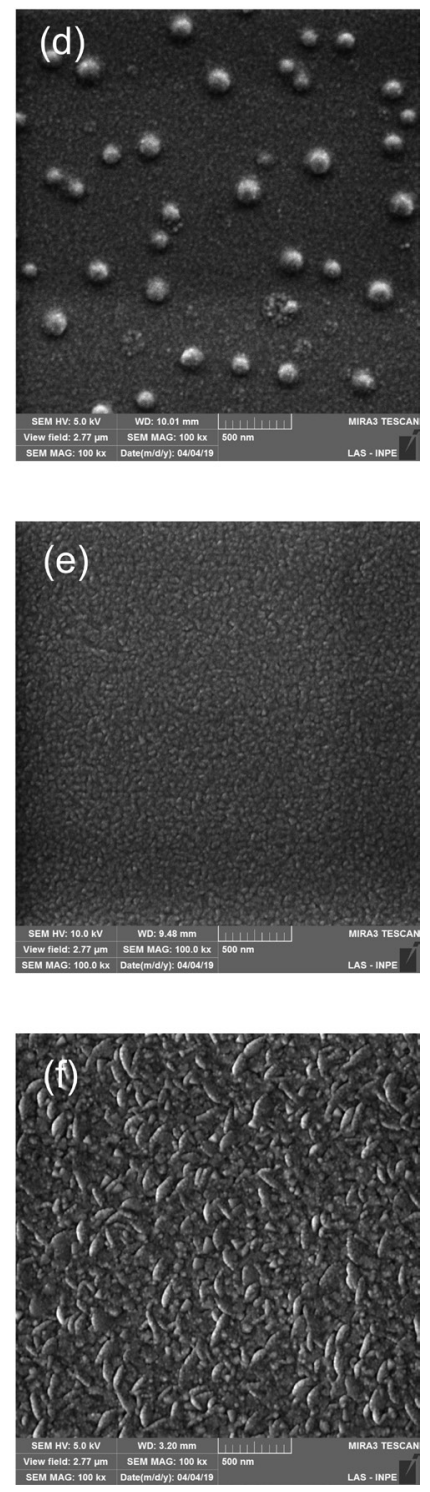

Figure 6. AFM and SEM topography images of GaN deposited on Si (100) at (a,d) $30 \mathrm{~W},(\mathrm{~b}, \mathrm{e}) 60 \mathrm{~W}$ and (c,f) $90 \mathrm{~W}$, respectively. 
Table 1. $R_{a}, R_{m s}$, and $R_{z}$ roughness parameters calculated from the AFM images.

\begin{tabular}{cccc}
\hline RF power & $R_{a}(\mathrm{~nm})$ & $R_{m s}(\mathrm{~nm})$ & $R_{z}(\mathrm{~nm})$ \\
\hline $30 \mathrm{~W}$ & $2.92 \pm 0.36$ & $5.97 \pm 0.16$ & $29.5 \pm 1.1$ \\
\hline $60 \mathrm{~W}$ & $3.02 \pm 0.18$ & $3.83 \pm 0.23$ & $16.3 \pm 1.5$ \\
\hline $90 \mathrm{~W}$ & $4.88 \pm 0.20$ & $6.22 \pm 0.23$ & $28.5 \pm 1.9$ \\
\hline
\end{tabular}

the $R_{m s}$ roughness (root mean square of heights and depths measured from a mean line, at $z=0$ ), which can be interpreted as the dispersion (standard deviation) of height and depths from the mean line, at $z=0$.

Despite the clusters formed at $30 \mathrm{~W}$, there was not significant difference between the $R_{a}$ 's for films generated at $30 \mathrm{~W}$ and $60 \mathrm{~W}$. That means, a significant variation was detected in the process of surface profile formation only for the sample obtained at $90 \mathrm{~W}$, which probably was responsible for the elongated structures. On the other hand, both the $R_{m s}$ and the $R_{z}$ parameters presented significantly higher values for the samples generated at $30 \mathrm{~W}$ and $90 \mathrm{~W}$, reflecting the effect of the clusters and the elongated structures on the surface profile. The real surface areas were also calculated for the AFM images with $4 \mu \mathrm{m}^{2}$ scanned area of Figure 6 and the results were $4.43 \mu \mathrm{m}^{2}, 4.53 \mu \mathrm{m}^{2}$, and $4.64 \mu \mathrm{m}^{2}$, for 30 , 60 and $90 \mathrm{~W}$, respectively.

\subsection{Vibrational and optical properties}

The Raman spectra of samples grown at $0.40 \mathrm{~Pa}$ and different RF powers are shown in Figure 7. Two main phonon modes were observed: $\mathrm{E}_{2}{ }^{\mathrm{H}}$, expected at $568 \mathrm{~cm}^{-1}$, and $\mathrm{A}_{1}(\mathrm{LO})$, expected at $734 \mathrm{~cm}^{-1}$, as indicated by the vertical dashed lines ${ }^{36,37}$. The second order of the $\mathrm{A}_{1}(\mathrm{LO})$ mode at $1470 \mathrm{~cm}^{-1}$, which presented a significant intensity, was also analyzed for all samples. It was still possible to identify a weak peak related to the $\mathrm{E}_{2}{ }^{\mathrm{L}}$ at the acoustic branch, expected at $\sim 144 \mathrm{~cm}^{-136}$. The small band at $\sim 320 \mathrm{~cm}^{-1}$ (gray dashed vertical line with an asterisk) is attributed to intrinsic lattice defects, commonly observed even in high quality monocrystalline $\mathrm{GaN}^{37}$.

The well-known Si substrate peak at $520 \mathrm{~cm}^{-1}$ was only observed for the sample grown at $30 \mathrm{~W}$, probably due to its thinner film thickness $(77 \mathrm{~nm})$ and high extinction coefficient (to be shown in the following) in the range of the excitation laser used ( $325 \mathrm{~nm}$ or $3.8 \mathrm{eV}$ ). This observation is supported by Kuball et $\mathrm{al}^{38}$, to whom the resonant Raman analysis (performed with $325 \mathrm{~nm}$ excitation laser, above the gap energy) is driven by the properties of the first $40 \mathrm{~nm}$ layer from the GaN surface.

This low-depth layer effect, in addition to the fact that all samples were composed of nanocrystallites 20-40 nm long, help to understand the overall Raman spectra similarities, despite the highlighted differences in the structural and morphological surface characteristics of these samples. The resonant Raman signal probably came mainly from the individual superficial nanocrystallites, being insensitive to the more long-range properties as texture and morphological.

The ellipsometry parameters, $I_{S}$ and $I_{C}$, and their model fitting curves are shown on Figure 8 . In the used setup, $I_{S}=\sin (2 \Psi) \sin (\Delta)$ and $I_{C}=\sin (2 \Psi) \cos (\Delta), \Psi$ and $\Delta$ being the ellipsometry angles. The interference fringes

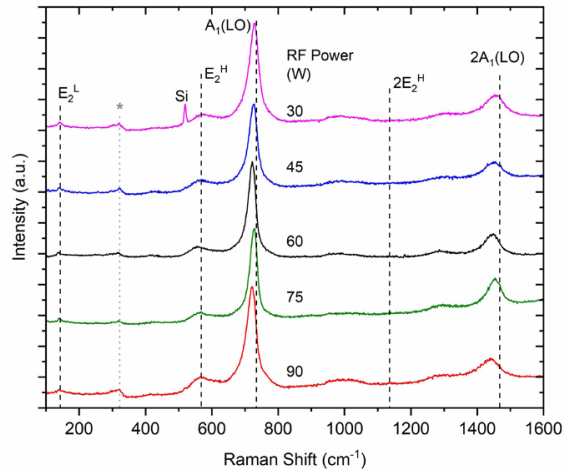

Figure 7. Raman spectra for samples deposited using $0.40 \mathrm{~Pa}$ working pressure, with different RF powers. Expected peak position for $\mathrm{E}_{2}(\mathrm{H})$ and $\mathrm{A}_{1}(\mathrm{LO})$ phonon modes are shown using dashed lines.
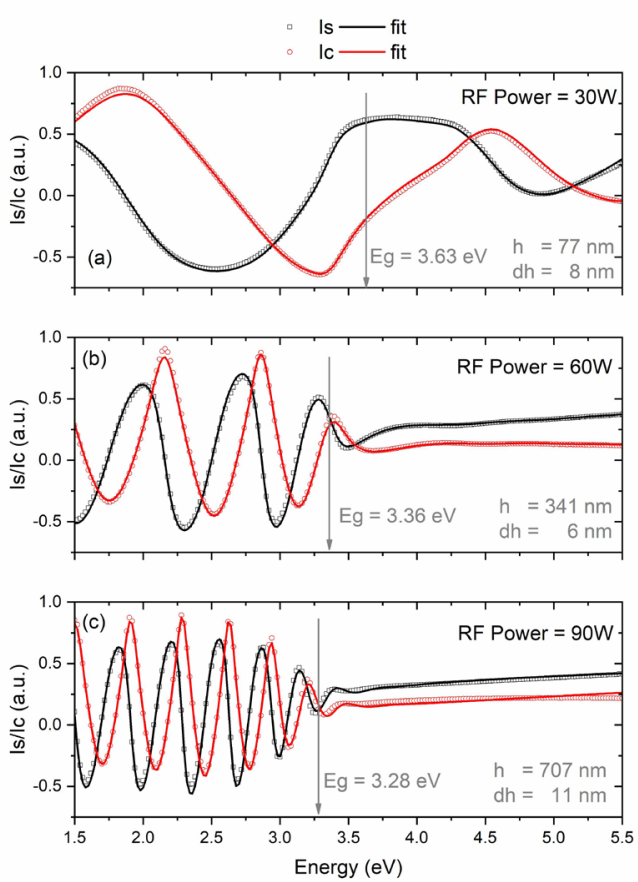

Figure 8. Ellipsometry parameters $I_{S}$ and $I_{C}$ (points) and fitted curves (lines) as a function of the photon energy for three representative samples grown at $0.40 \mathrm{~Pa}$ and (a) 30, (b) 60 and (c) $90 \mathrm{~W}$. The vertical arrows indicate the resulting gap energy $\left(\mathrm{E}_{\mathrm{g}}\right)$ after proper modeling fit. The total thickness of the film (h) as well as the thickness of the top layer (dh) used to simulate the roughness (composed by $50 \% \mathrm{GaN}+50 \%$ air) are also displayed in the respective graphs.

of all samples showed good regularity, indicating good film homogeneity and well-defined interfaces, allowing very small minimized chi-squared values (below 2.8) and reliable thicknesses values, that corroborated with the ones measured by mechanical profilometry. The thicknesses $d h$ of the roughness layers (top layer of the model) of all samples 
stayed in range from $6 \mathrm{~nm}$ (sample grown with $60 \mathrm{~W}$ ) to $11 \mathrm{~nm}$ (sample grown with $90 \mathrm{~W}$ ).

The measured refractive index (n) and extinction coefficient (k) can be seen in Figure 9. All samples showed a GaN-like normal dispersions ${ }^{39}$. Samples deposited at $0.40 \mathrm{~Pa}$ and different RF powers presented refractive index curves similar to the expected for single crystal $\mathrm{GaN}^{33}$. However, a decrease on the refractive index can be observed with an expressive increase on the work pressure (from 0.40 to 1.33 , over 3 times), which is characteristic of amorphous and voided materials, that could also explain the smother $\mathrm{k}$ rise near the gap energy $(\sim 3.4 \mathrm{eV})$, for that sample.

On the other hand, the samples grown at $0.40 \mathrm{~Pa}$, mainly for RF power $<75 \mathrm{~W}$, exhibited sharper $\mathrm{k}$ curves that results in well-defined gap energy values, close to the expected for $\mathrm{GaN}(3.42 \mathrm{eV})^{39}$, as shown in Figure 10. Exception for the sample grown with $30 \mathrm{~W}$, that shows a large band gap of $3.62 \mathrm{eV}$, which could be holding a significant uncertainty due to its low thickness $(\sim 77 \mathrm{~nm})$ : note in Figure 8 that the interference fringes do not define the gap for $30 \mathrm{~W}$ as the others do, and indicate that its peculiar morphology (Figure 6a and d) is not well described by a simple roughness layer on the ellipsometric mathematical model, shifting down the entire k-curve, as compared to that obtained for $60 \mathrm{~W}$.

\subsection{Discussion on the effects of working pressure and $R F$ power}

From the used deposition conditions, the estimated mean free paths of the plasma species are $\sim 40 \mathrm{~mm}$ for $0.40 \mathrm{~Pa}$ and $\sim 6 \mathrm{~mm}$ for $2.67 \mathrm{~Pa}$ (atmosphere temperature taking as $200^{\circ} \mathrm{C}$, the same as temperature of the magnetron shield as measured by a thermocouple). Considering the $90 \mathrm{~mm}$ distance from target to substrate, the average number of collisions from target to substrate would then be $\sim 3$ for $0.40 \mathrm{~Pa}$ and $\sim 20$ for 2.67 $\mathrm{Pa}$. Thus, it is expected that for $0.40 \mathrm{~Pa}$ the energetic particles are reaching the growing film surfaces with energy distribution very close to the original values as emerged from the target. These latter values, known to be 100, 20 and $20 \mathrm{eV}$ for $\mathrm{N}$ and $\mathrm{Ar}$, and Ga target-emitted atoms according to calculations performed by Schiaber et al. ${ }^{10}$. On the other hand, for high pressures (1.33 and 2.67 Pa for example), the energetic particles originated from the target are expected to lose a significant fraction of their kinetic energy before reaching the substrates, probably going under 60,4 and $3 \mathrm{eV}(\mathrm{N}$ and $\mathrm{Ar}$, and $\mathrm{Ga}$ ), obtained for $2.0 \mathrm{~Pa}$ and $50 \mathrm{~mm}$ distance used in ${ }^{10}$. Besides, it is assumed that the better crystal quality observed for the $0.40 \mathrm{~Pa}$ film (Figure 3) is mainly attributed to the achievement of the energy-enhanced growth regime where the precursors average kinetic energies reach a minimal value to improve the adatoms surface diffusion length, allowing them to incorporate in lower energy sites. The collateral conditions of this low-pressure growth are also beneficial by assuring metallic sputtering mode (non-poisoned regime), high growth rate and low levels of contaminations.

The increasing RF power by itself or combined with the increasing film thickness is responsible for a significant decrease of the $c$-orientation degree. Considering only the thickness effect based on the van der Drift model ${ }^{40}$, the opposite result could be expected: thinner films would be composed by the first nucleation layers, and those would

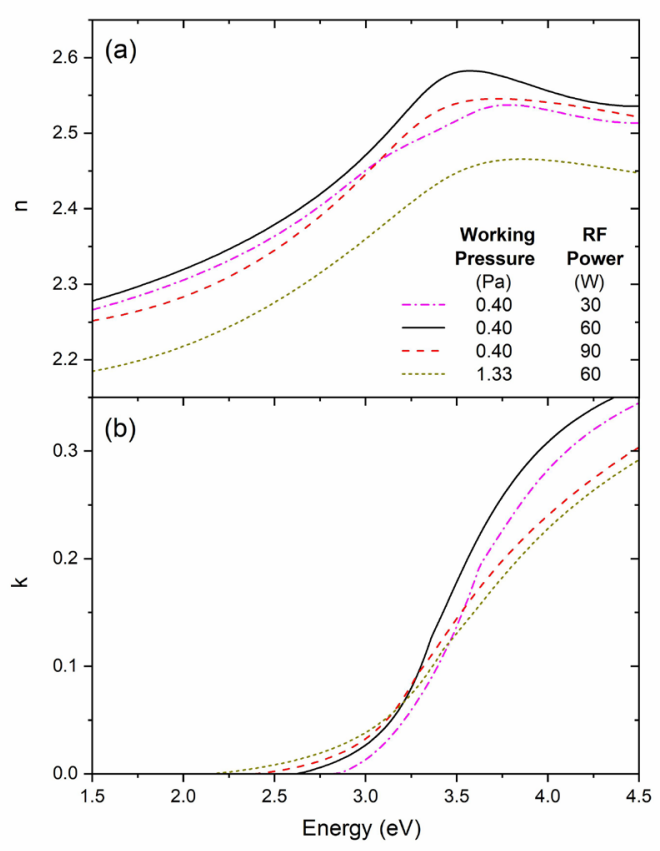

Figure 9. Curves of (a) refraction index dispersion $n$ and (b) extinction coefficient $\mathrm{k}$ versus photon energies for representative samples.

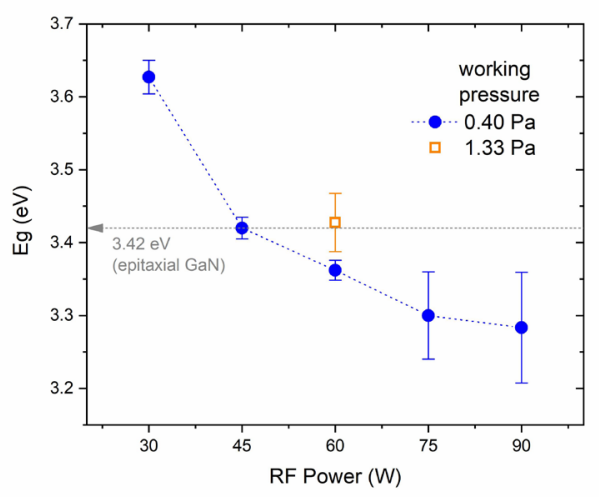

Figure 10. Band-gap energy $\left(\mathrm{E}_{\mathrm{g}}\right)$ versus the RF power, for the samples grown at $0.40 \mathrm{~Pa}$ together with that grown with $1.33 \mathrm{~Pa}$ $(60 \mathrm{~W})$. The horizontal arrow indicates the expected $\mathrm{E}_{g}$ value for epitaxial $\mathrm{GaN}^{39}$.

be mostly randomly oriented. As the thickness increase, the crystallites with fast growth direction aligned with the film growth direction would dominate the composition of the film, and result in a highly oriented film. Thus, it is likely that the RF power (and its direct related modifications in the growth dynamics) is dominating the observed decrease of the $c$-orientation and interfering in the crystallites sizes as measures in the same $<0001>$ or $c$-axis direction.

The first aspect to consider when increasing RF power on the growth dynamics is the increase of the impinging flux of the precursors and thus the deposition rate, which would 
limit the surface diffusion length of the adsorbed precursors - burial regime ${ }^{41}$, harming the nucleation process and the individual crystallite growth process. On the other hand, lower RF power would then improve nucleation process by allowing higher times for surface diffusion, eventually resulting in larger and more separated nucleus and stronger texture, helping to understand the strong c-orientation and the appearance of separated island in the low RF power limit.

Hence, it is considered here that the overall morphological and optical quality, mainly the preferred $c$-orientation degree of the obtained GaN films is strictly linked to the surface diffusion length of the adsorbed species during nucleation and posterior crystallite growth. The arrival of energetic particles with kinetic energies well above the thermal source is allowed by the low working pressure $(0.40 \mathrm{~Pa})$ used, and the relatively high adsorbent diffusion length is permitted by the relatively low deposition rate (RF power from 30 to $60 \mathrm{~W})$. By increasing the RF power above $60 \mathrm{~W}$, the surface diffusion is limited by the increase of the deposition rate, privileging higher nucleation density with a more random orientation in detriment of the final crystallite sizes. However, the short-range order of the obtained crystallites, as demonstrated by the resonant Raman results, seems to be independent of the morphology and have quality comparable to that of epitaxial $\mathrm{GaN}^{37}$. It is important to emphasize that other deposition parameters, mainly substrate temperature and target-substrate distance are strongly correlated to the working pressure and RF power in the discussion of energetic growth and surface diffusion.

\section{Conclusions}

A new reactive sputtering setup dedicated to $\mathrm{GaN}$ and related compounds is presented. Its special features allowed the growth of $\mathrm{GaN}$ films onto Si substrates kept at relatively low temperature $\left(400^{\circ} \mathrm{C}\right)$, using a liquid $\mathrm{Ga}$ target and $\mathrm{Ar}+$ $\mathrm{N}_{2}$ plasma. It was demonstrated that, even using a $\mathrm{N}_{2}$-rich atmosphere plasma $(67 \%)$, the target poisoning can be avoided by using a suitable Ar injection ring directed to the Ga surface. This feature has also allowed the achievement of very low deposition pressure of $0.40 \mathrm{~Pa}$, which resulted in high crystallized films over a variety of RF power applied to the Ga target.

The structural, morphological, vibrational, and optical properties of the samples were extensively studied by means of XRD, AFM, SEM, Raman and spectroscopic ellipsometry. The crystallinity of the films shows strong dependence on the working pressure, the lower pressure limit $(0.40 \mathrm{~Pa})$ resulting in nanocrystalline films, with remarkable c-axis texture, while higher pressures $(\geq 0.67 \mathrm{~Pa})$ resulted in predominantly amorphous films. The RF power applied to the Ga target has also shown an important trend to the morphological properties of the GaN/Si films, in a way that its increasing value from 30 to $90 \mathrm{~W}$ tends to decrease the c-axis texture, and also to decrease the optical gap. On the other hand, the vibrational properties, as measured by resonant Raman spectroscopy, do not show any clear correlation to the other properties nor to the deposition parameters here studied.

Given the overall results, and considering the surface roughness as measured by AFM and SEM, it is stated that the optimal condition for $\mathrm{GaN}$ growth onto $\mathrm{Si}$ (100) substrates kept at $400^{\circ} \mathrm{C}$ is that with working pressure of $0.40 \mathrm{~Pa}$ and RF power of $60 \mathrm{~W}$, which rendered a reasonable growth rate of $2.5 \mathrm{~nm} / \mathrm{min}$.

\section{Acknowledgments}

The authors thank the financial support of Fapesp [Grants 2015/06241-5, 2011/50773-0], CNPq [Grants 428591/20183, 159754/2018-6 and 307199/2018-5], CAPES [Grants 88881.122156/2016-01 and 8887.157419/2017-00] and FINEP Brazilian agencies.

\section{References}

1. Leszczynski M, Teisseyre H, Suski T, Grzegory I, Bockowski M, Jun J, et al. Lattice parameters of gallium nitride. Appl Phys Lett. 1996;69(1):73-5. http://dx.doi.org/10.1063/1.118123.

2. Strite S, Morkoç H. GaN, AlN, and InN: a review. J Vac Sci Technol B: Nanotechnol Microelectron. [Internet]. 1992 [cited 2021 Aug 27];10(4):1237-66. Available from: http://scitation. aip.org/content/avs/journal/jvstb/10/4/10.1116/1.585897

3. Nakamura $\mathrm{S}$. Current status of GaN-based solid-state lighting. MRS Bull. 2009;34(02):101-7. http://dx.doi.org/10.1557/ mrs2009.28.

4. Zhang B, Liu Y. A review of GaN-based optoelectronic devices on silicon substrate. Chin Sci Bull. 2014;59(12):1251-75.

5. Greco G, Iucolano F, Roccaforte F. Review of technology for normally-off HEMTs with p-GaN gate. Mater Sci Semicond Process. 2017;2018(78):96-106. http://dx.doi.org/10.1016/j. mssp.2017.09.027.

6. Muller A, Neculoiu D, Konstantinidis G, Deligeorgis G, Dinescu A, Stavrinidis A, et al. SAW devices manufactured on GaN/ $\mathrm{Si}$ for frequencies beyond $5 \mathrm{GHz}$. IEEE Electron Device Lett. 2010;31(12):1398-400.

7. Miškinis R, Jokubauskis D, Urba E, Smirnov D, Gaidamovičiute $\mathrm{L}$, Mikalauskas K, et al. Investigation of a GaN-based SAW oscillator with respect to UV illumination and temperature. Acta Phys Pol A. 2015;127(1):90-2.

8. Abdallah B, Jazmati AK, Refaai R. Oxygen effect on structural and optical properties of $\mathrm{ZnO}$ thin films deposited by $\mathrm{RF}$ magnetron sputtering. Mater Res. 2017;20(3):607-12.

9. Jazmati AK, Abdallah B. Optical and structural study of $\mathrm{ZnO}$ thin films deposited by RF magnetron sputtering at different thicknesses: a comparison with single crystal. Mater Res. 2018;21(3):1-6.

10. Schiaber ZS, Leite DMG, Bortoleto JRR, Lisboa-Filho PN, da Silva JHD. Effects of substrate temperature, substrate orientation, and energetic atomic collisions on the structure of GaN films grown by reactive sputtering. J Appl Phys. 2013;114(18):183515.

11. Joblot $S$, Semond F, Natali F, Vennéguès $P$, Laügt $M$, Cordier Y, et al. Growth of wurtzite-GaN on silicon (100) substrate by molecular beam epitaxy. Phys Status Solidi C Conf. 2005;2(7):2187-90.

12. Feng Y, Yang X, Zhang Z, Kang D, Zhang J, Liu K, et al. Epitaxy of single-crystalline GaN film on CMOS-compatible $\mathrm{Si}(100)$ substrate buffered by graphene. Adv Funct Mater. 2019;29(42):1905056.

13. Dadgar A, Schulze F, Wienecke M, Gadanecz A, Bläsing J, Veit P, et al. Epitaxy of GaN on silicon - Impact of symmetry and surface reconstruction. New J Phys. 2007;9:389.

14. Chung JW, Ryu K, Lu B, Palacios T. GaN-on-Si technology, a new approach for advanced devices in energy and communications. In: European Conference on Solid-State Device Research (ESSDERC); 2010 Sept.14-16; Seville. Procceedings. Piscataway: IEEE; 2010. p. 52-6.

15. Radtke G, Couillard M, Botton GA, Zhu D, Humphreys CJ. Scanning transmission electron microscopy investigation of 
the $\mathrm{Si}(111) / \mathrm{AlN}$ interface grown by metalorganic vapor phase epitaxy. Appl Phys Lett. 2010;97(25):251901.

16. Duquenne C, Djouadi MA, Tessier PY, Jouan PY, Besland MP, Brylinski C, et al. Epitaxial growth of aluminum nitride on AlGaN by reactive sputtering at low temperature. Appl Phys Lett. 2008;93(5):52905.

17. Sato K, Ohta J, Inoue S, Kobayashi A, Fujioka H. Roomtemperature epitaxial growth of high quality AIN on $\mathrm{SiC}$ by pulsed sputtering deposition. Appl Phys Express. 2009;2(1):11003.

18. Junaid M, Id CH, Chen Y, Ola P, Persson Å, Hultman L, et al. Effects of $\mathrm{N} 2$ partial pressure on growth, structure, and optical properties of gan nanorods deposited by liquid-target reactive magnetron sputter epitaxy. Nanomaterials. 2018;8:223.

19. Watanabe T, Ohta J, Kondo T, Ohashi M, Ueno K, Kobayashi A, et al. AlGaN/GaN heterostructure prepared on a $\mathrm{Si}(110)$ substrate via pulsed sputtering. Appl Phys Lett. 2014;104(18):182111.

20. Kobayashi A, Ohta J, Fujioka H. Pulsed sputtering epitaxial growth of m-plane InGaN lattice-matched to $\mathrm{ZnO}$. Sci Rep. 2017;7(1):1-6. http://dx.doi.org/10.1038/s41598-017-12518-w.

21. Prabaswara A, Birch J, Junaid M, Serban EA, Hultman L, Hsiao CL. Review of GaN thin film and nanorod growth using magnetron sputter epitaxy. Appl Sci. 2020;10(9):3050.

22. Muller A, Konstantinidis G, Giangu I, Adam GC, Stefanescu A, Stavrinidis A, et al. GaN membrane supported SAW pressure sensors with embedded temperature sensing capability. IEEE Sens J. 2017;17(22):7383-93.

23. Dow ABA, Kherani NP, Ahmed A, Schmid U. Nanocrystalline Diamond / AlN Structures for High Efficient SAW NanoResonators. In: Proc ISAF-ECAPD-PFM 2012; 2012 July 9-13; Aveiro. Procceedings. Piscataway: IEEE; 2012.

24. Woods RC, Boroumand FA. Epitaxially grown GaN thin-film SAW filter with high velocity and low insertion loss. IEEE Trans Electron Dev. 2006;53(1):173-6.

25. Izyumskaya N, Avrutin V, Ding K, Özgür Ü, Morkoç H, Fujioka H. Emergence of high quality sputtered III-nitride semiconductors and devices. Semicond Sci Technol. 2019;34(9):093003.

26. Furqan CM, Ho JYL, Kwok HS. GaN thin film: growth and characterizations by magnetron sputtering. Surf Interfaces. 2021;26:101364. http://dx.doi.org/10.1016/j.surfin.2021.101364.

27. Leite DMG, Pereira ALJ, Silva LF, Silva JHD. Nanocrystalline $\mathrm{GaN}$ and $\mathrm{GaN}: \mathrm{H}$ films grown by RF-magnetron sputtering. Braz J Phys. 2006;36(3B):978-81.

28. Guo QX, Lu WJ, Zhang D, Tanaka T, Nishio M, Ogawa H. Growth condition dependence of structure and surface morphology of GaN films on (111)GaAs substrates prepared by reactive sputtering. J Vac Sci Technol [Internet]. 2004 [cited 2021 Aug 27];22(4):1290-2. Available from: http://scitation. aip.org/content/avs/journal/jvsta/22/4/10.1116/1.1765133.

29. Silva JHD, Leite DMG, Tabata A, Cavalheiro AA, Silva JHD, Leite DMG, et al. Structural and vibrational analysis of nanocrystalline Ga1-xMnxN films deposited by reactive magnetron sputtering. J Appl Phys. 2007;102(6):63526.

30. Berg S, Nyberg T. Fundamental understanding and modeling of reactive sputtering processes. Thin Solid Films [Internet]. 2005 [cited 2021 Aug 27];476(2):215-30. Available from: http://www. sciencedirect.com/science/article/pii/S0040609004016876.

31. Adachi S, Mori H, Ozaki S. Model dielectric function for amorphous semiconductors. Phys Rev B Condens Matter Mater Phys. 2002;66:153201.

32. Schulz H, Thiemann KH. Crystal structure refinement of AlN and GaN. Solid State Commun [Internet]. 1977 Sep 1 [cited 2019 Nov 11];23(11):815-9. Available from: https://www. sciencedirect.com/science/article/pii/0038109877909590.

33. Yadav BS, Major SS, Srinivasa RS. Growth and structure of sputtered gallium nitride films. J Appl Phys. 2007;102(7)

34. Lagerstedt $\mathrm{O}$, Monemar B. Variation of lattice parameters in $\mathrm{GaN}$ with stoichiometry and doping. Phys Rev B Condens Matter. 1979;19(6):3064-70.

35. Birkholz M. Thin film analysis by $\mathrm{x}$-ray scattering. Weinheim: Wiley-VCH; 2006.

36. Chuah LS, Hassan Z, Hassan HA. Optical characterization of $\mathrm{GaN}$ thin film grown on Si (111) by radio-frequency plasmaassisted molecular beam epitaxy. MJISAT. 1989;12-15.

37. Harima H. Properties of $\mathrm{GaN}$ and related compounds studied by means of Raman scattering. J Phys Condens Matter. 2002;14(38):R967-93.

38. Kuball M. Raman spectroscopy of GaN, AlGaN and AlN for process and growth monitoring/control. Surf Interface Anal. 2001;31(10):987-99.

39. Muth J, Johnson M, Kolbas RM. Absorption coefficient and refractive index of GaN, AIN and AlGaN alloys. Mat Res Soc Symp Proc. 1999;537:G5.2.

40. Van Der Drift A. Evolutionary selection, a principle governing growth orientation in vapour-deposited layers. Philips Res Rep. 1967;22(3):267.

41. Smith DL. Thin film deposition: principles and practice. Boston: McGraw-Hill Inc.; 1995. 